\title{
BACE1 Regulates Proliferation and Neuronal Differentiation of Newborn Cells in the Adult Hippocampus in Mice
}

\author{
Zena K. Chatila, ${ }^{1 *}$ 'Dunhee Kim, ${ }^{1 "}$ Clara Berlé, ${ }^{1 *}$ Enjana Bylykbashi, ${ }^{1}$ Alexander Rompala, ${ }^{1}$ Mary K. \\ Oram, ${ }^{1}$ Drew Gupta, ${ }^{1}$ Sang Su Kwak, ${ }^{1}$ Young Hye Kim, ${ }^{2}$ Doo Yeon Kim, ${ }^{1}$ De Hoon Choi, ${ }^{1}$ and \\ Rudolph E. Tanzi ${ }^{1}$
}

DOI:http://dx.doi.org/10.1523/ENEURO.0067-18.2018

${ }^{1}$ Genetics and Aging Research Unit, Department of Neurology, Massachusetts General Hospital, Harvard Medical School, Charlestown, Massachusetts 02129, and ${ }^{2}$ Biomedical Omics Group, Korea Basic Science Institute, Cheongju-si, Chungbuk 363-883, Republic of Korea

\begin{abstract}
$\beta$-Site amyloid precursor protein cleaving enzyme 1 (BACE1) is required for the production of $\beta$-amyloid (A $\beta$ ), one of the major pathogenic molecules of Alzheimer's disease (AD), and is therefore being actively pursued as a drug target for $A D$. Adult hippocampal neurogenesis $(A H N)$ is a lifelong process that is known to be important for learning and memory and may have the potential to regenerate damaged neural tissue. In this study, we examined whether BACE1 regulates $A H N$, which holds important implications for its suitability as a drug target in AD. Cohorts of 2-month-old wild-type (BACE $1^{+/+}$), heterozygous, and homozygous BACE1 knockout mice (BACE1 ${ }^{+/-}$and BACE1 ${ }^{-/}$, respectively) were injected with 5-bromo-2'-deoxyuridine (BrdU) and sacrificed 1 day later to examine the impact of loss of BACE1 on neural precursor cell (NPC) proliferation in the adult brain. Parallel cohorts of mice were sacrificed 4 weeks after BrdU injection to determine the effects of BACE1 on survival and differentiation of newborn NPCs. We found that NPC proliferation was increased in $\mathrm{BACE} 1^{-/}$mice compared to $\mathrm{BACE} 1^{+/+}$mice, while no difference was observed in NPC survival across genotypes. Differentiation of NPCs to neuronal lineage was impaired in BACE $1^{-1-}$ mice. However, no differences were observed in astrogenesis, the proportion of immature neurons, or the production of oligodendrocytes across genotypes. Importantly, corresponding with a decrease in neuronal differentiation in the absence of a complementary increase in an alternate cell fate, $\mathrm{BACE} 1^{-/-}$mice were found to have a pool of undifferentiated NPCs in the hippocampus compared to BACE1 ${ }^{+/+}$and BACE1 ${ }^{+/-}$mice.
\end{abstract}

Key words: Adult neurogenesis; Alzheimer's disease; BACE1; hippocampus

\section{Significance Statement}

The present findings not only demonstrate that BACE1 regulates AHN, but also raise a note of caution that therapeutic inhibition of its enzymatic activity might have the potential to produce a pool of adult-generated undifferentiated cells in the hippocampus. Our data strongly suggest that the complete loss of BACE1 activity dysregulates AHN in the adult mouse hippocampus. Alternatively, partial inhibition of BACE1 activity, e.g., in $B A C E 1^{+/-}$mice, may mirror a more suitable therapeutic approach that would not impact AHN or NPC differentiation, for when BACE1 inhibition is being pursued as an effective means of lowering A $\beta$ levels in AD.

\section{Introduction}

$\beta$-Site amyloid precursor protein cleaving enzyme 1 (BACE1) is required for the production of $\beta$-amyloid 42

Received February 7, 2018; accepted June 25, 2018; First published July 30, 2018.

The authors declare no competing financial interests.
(A $\beta 42 ;$ Tanzi and Bertram, 2005). When produced excessively, $A \beta 42$ aggregates to form amyloid plaques, a pathologic hallmark of Alzheimer's disease (AD). Impor- 
tantly, amyloid pathology is absent in transgenic AD mice crossed with those lacking the BACE1 gene. As a result, down-regulation of BACE1 activity is being investigated to treat or prevent AD (Vassar, 2014). However, endogenous roles of BACE1 have yet to be fully determined, and it is possible that inhibiting BACE1 may compromise neural function. It is therefore critical to understand the physiologic functions of BACE1 to fully comprehend the effects of manipulating BACE1 activity.

The human hippocampus contains neural progenitor cells (NPCs) that continue to generate substantial levels of new neurons at a steady rate well into old age, with only a modest decline (Eriksson et al., 1998; Spalding et al., 2013). This process is known as adult hippocampal neurogenesis (AHN). AHN is believed to underlie mechanisms of neural plasticity, learning, and memory, and may be critical for regeneration of damaged neural tissue (Zhao et al., 2008; Ming and Song, 2011; Aimone et al., 2014). It has been shown that $A H N$ is altered in early stages of $A D$ in various $A D$ transgenic animal models ( $M u$ and Gage, 2011).

BACE1 is known to regulate neurogenesis in early developmental stages (Hu et al., 2013). Additionally, sAPP $\beta$, a direct product of the cleavage of the amyloid precursor protein (APP) by BACE1, also regulates proliferation and differentiation of neural precursor cells (NPCs) in vitro (Freude et al., 2011; Baratchi et al., 2012). Neuregulin 1, which is cleaved by BACE1, has been shown to regulate AHN (Mahar et al., 2016). However, the involvement of BACE1 in regulating AHN, which holds important implications for its suitability as a drug target in $A D$, has yet to be determined. In the present study, we investigated whether BACE1 plays critical roles in AHN by examining proliferation, survival, and differentiation of newborn cells in the dentate gyrus (DG) of BACE1 knockout (KO) mice. Determining whether BACE1 activity regulates AHN will help to elucidate whether therapeutically decreasing the activity of this enzyme will further impair neuronal functioning in $A D$.

\section{Materials and methods}

\section{Animals}

Heterozygous BACE1 KO mice $\left(\mathrm{BACE}^{+/-}\right.$, B6SJL129 $\times \mathrm{C} 57 \mathrm{BI} / 6$ mixed background) were kindly provided by the laboratory of Dr. Mark Albers (Massachusetts General Hospital) and maintained in our facility by crossing male

Funding sources: Cure Alzheimer's Fund. Dr. Young Hye Kim was supported by the Ministry of Science and ICT of Korea (NRF-2016R1A2B4015694).

*Z.K.C., E.K., and C.B. contributed equally to this work.

Acknowledgments: We thank Drs. Virginie Buggia-Prevot (University of Texas MD Anderson) and Carla D'Avanzo (MGH) for helpful discussion.

Correspondence should be addressed to either of the following: Rudolph E. Tanzi, Genetics and Aging Research Unit, Massachusetts General Hospital, 114 16th St, Charlestown, MA 02129. E-mail: tanzi@helix.mgh.harvard.edu; or Se Hoon Choi, Massachusetts General Hospital, 114 16th St, Charlestown, MA 02129. E-mail: Choi.SeHoon@mgh.harvard.edu.

DOI:http://dx.doi.org/10.1523/ENEURO.0067-18.2018

Copyright @ 2018 Chatila et al.

This is an open-access article distributed under the terms of the Creative Commons Attribution 4.0 International license, which permits unrestricted use, distribution and reproduction in any medium provided that the original work is properly attributed. and female heterozygous mice. Male wild-type $\left(\mathrm{BACE}^{+/+}\right.$mice), BACE1 ${ }^{+/-}$, and homozygous BACE1 $\mathrm{KO}\left(\mathrm{BACE}^{-1-}\right)$ mice were used for this study. Animals were housed with a 12-h:12-h light-dark cycle and with food and water provided ad libitum. All animal procedures were performed in accordance with Massachusetts General Hospital animal care committee's regulations.

\section{Immunohistochemistry for BACE1}

$\mathrm{BACE} 1^{+/+}, \mathrm{BACE} 1^{+/-}$, and $\mathrm{BACE} 1^{-/-}$mice were deeply anesthetized with isoflurane and perfused transcardially with $0.9 \% \mathrm{NaCl}$ followed by $4 \%$ paraformaldehyde (PFA) in cold $0.1 \mathrm{M}$ phosphate buffer $(\mathrm{pH} 7.4)$. The brains were postfixed overnight in 4\% PFA and then transferred into $30 \%$ sucrose and kept there until they sank. Brains were sectioned coronally at $40 \mu \mathrm{m}$ with a sliding freezing microtome (SM 2010R, Leica Biosystems). The brain sections were stained by rabbit anti-BACE1 (D10E5, 1:400, Cell Signaling Technology). The immunohistochemical staining was made using the avidin-biotin complex (ABC) system (Vectastain Elite, Vector Labs) and nickelenhanced diaminobenzidine (DAB) incubation. Sections were mounted on gelatin-coated slides, air-dried, dehydrated through a graded alcohol series, cleared, and coverslipped for microscopic examination.

\section{5-Bromo-2'-deoxyuridine injection and quantification and phenotype of newborn cells}

5-Bromo-2' -deoxyuridine (BrdU; Sigma) was dissolved in $0.9 \% \mathrm{NaCl}$ at a concentration of $20 \mathrm{mg} / \mathrm{ml}$ and was filtered $(0.2 \mu \mathrm{m})$ under sterile conditions. Mice received a single i.p. injection of BrdU (100 mg/kg, Sigma) at the age of 2 months. Half of the mice in each group were sacrificed $1 \mathrm{~d}$ after the injection to determine progenitor proliferation. The remaining mice were sacrificed 4 weeks after the BrdU injection to determine survival and neuronal differentiation of the newborn cells.

Immunofluorescent labeling for BrdU, neuronal nuclei $(\mathrm{NeuN})$, doublecortin (DCX), glial fibrillary acidic protein (GFAP), and Olig2 (O2) was performed. The antibodies used were as follows: rat anti-BrdU (1:100, Accurate Chemical \& Scientific Corp.), mouse anti-NeuN (1:500, Millipore Bioscience Research Reagents), goat anti-DCX (1:200, Santa Cruz Biotechnology), rabbit anti-GFAP (1: 500, Dako), and rabbit anti-O2 (1:100, Abcam). The fluorescent secondary antibodies used were donkey anti-rat IgG conjugated with Cy2; donkey anti-mouse IgG conjugated with Cy3 or Cy5; donkey anti-goat IgG conjugated with Cy3 or Cy5; donkey anti-rabbit IgG conjugated with Cy3 or Cy5 (all 1:250, Jackson ImmunoResearch).

For BrdU staining, DNA was denatured by incubating the sections for $2 \mathrm{~h}$ in $50 \%$ formamide/ $2 \times$ SSC $(0.3 \mathrm{M}$ $\mathrm{NaCl}$ and $0.03 \mathrm{~m}$ sodium citrate) solution at $65^{\circ} \mathrm{C}$. Sections were rinsed for $15 \mathrm{~min}$ in $2 \times \mathrm{SSC}$ and incubated for 30 min in $2 \mathrm{~N} \mathrm{HCl}$ at $37^{\circ} \mathrm{C}$. The acid was neutralized by rinsing the sections for $10 \mathrm{~min}$ in $0.1 \mathrm{M}$ boric acid $(\mathrm{pH} 8.5)$ followed by several washes in Tris-buffered saline (TBS, $\mathrm{pH}$ 7.5). Tissues were then mounted with polyvinyl alcohol with diazabicyclo-octane (PVA-DABCO, Sigma) for viewing and imaging with a Nikon Eclipse Ti confocal laser scanning microscope (Nikon Instruments). 
To estimate the total number $\mathrm{BrdU}^{+}$cells, every sixth brain section was systematically selected for immunostaining, and $\mathrm{BrdU}^{+}$cells in the subgranular and granular cell layers were counted. Resulting numbers were multiplied by six to obtain the estimated total number of $\mathrm{BrdU}^{+}$ cells per animal. For colabeling analysis of differentiated $\mathrm{BrdU}^{+}$cell types with lineage-specific markers, the phenotypes of $15-20 \mathrm{BrdU}^{+}$cells per animal were determined. The total number of $\mathrm{GFAP}^{+}$cells in the DG was counted in every sixth brain section, and GFAP signal intensity (integrated density) was measured by $\mathrm{NIH} \mathrm{Im-}$ ageJ software.

\section{Quantification of $\mathrm{Ki}^{+} \mathrm{7}^{+}$cells}

Immunofluorescent labeling for Ki67 was performed using rabbit anti-Ki67 antibodies (1:100, Abcam) and donkey anti-rabbit IgG conjugated with Cy3 (1:250, Jackson ImmunoResearch). 4',6-Diamidino-2-phenylindole (DAPI) counterstaining was performed to measure DG volume using a NIS-Elements AR (Nikon Instruments). Every sixth brain section was systematically selected for immunostaining, and $\mathrm{Ki}^{+} 7^{+}$cells in the subgranular and granular cell layers were counted. The $\mathrm{Ki} 67^{+}$cell counts were expressed and analyzed as the number of total Ki67 ${ }^{+}$ cells divided by the DG volume to normalize for variations across mice; $\mathrm{BACE} 1^{-/}$mice showed smaller sizes of brain and DG than BACE $1^{+/+}$and BACE $1^{+/-}$mice.

\section{Immunoblot analysis}

Hippocampal tissues were homogenized in extraction buffer containing $2 \%$ SDS and $1 \%$ Triton. $50 \mu \mathrm{g}$ of protein were resolved on $12 \%$ Bis-Tris or $4 \%-12 \%$ gradient Bis/ Tris gels (Life Technologies), and the proteins were transferred to nylon membranes (Bio-Rad). Immunoblot images were visualized by enhanced chemiluminescence $(E C L)$. The images were captured by using BioMax film (Kodak) or VersaDoc imaging system (Bio-Rad). The following primary antibodies were used: full-length APP (C66, a gift from Drs. Dora M. Kovacs and Doo Yeon Kim at Massachusetts General Hospital), APP-CTF $\alpha$ (C66), APP-CTF $\beta$ (C66), BACE1 (D10E5, Cell Signaling Technology), and $\beta$-actin (Sigma).

\section{Statistics}

Data are expressed as mean values \pm SEM. Error bars in the figures represent SEM. Differences between groups were analyzed using ANOVA followed by a post hoc comparison using Tukey. Statistical analysis was performed using PRISM GraphPad statistical software. In all cases, $p=0.05$ was considered statistically significant.

\section{Results}

\section{Lack of BACE1 expression in BACE1 $1^{-/}$mice}

BACE1 expression was assessed through immunohistochemistry to confirm the lack of BACE1 expression in $B A C E 1^{-/}$mice. In BACE1 ${ }^{+/+}$brain tissues, diffuse BACE1 immunoreactivity was present throughout entire sections, and was higher in the mossy fiber pathway of the hippocampus (Fig. 1A), as previously reported (Zhao et al., 2007). In BACE $1^{+/}$mice, BACE1 immunoreactivity was reduced but still present in the mossy fiber pathway, but no BACE1 immunoreactivity was observed in brain sections from $\mathrm{BACE}^{-/-}$mice.

$\mathrm{BACE} 1^{+/+}, \mathrm{BACE} 1^{+/-}$, and BACE $1^{-/-}$brain tissues were also assessed for BACE1 expression through Western blot analysis (Fig. 1B). As expected, BACE1 was robustly expressed in BACE1 $1^{+/+}$brain tissues, weakly expressed in BACE1 ${ }^{+/-}$tissues, and not expressed in BACE1 $1^{-/}$tissues. To assess BACE1 activity, brain tissues were also examined for the $\mathrm{C}$-terminal APP fragment $\beta$ subunit (APP-CTF $\beta$ ), a product of its enzymatic cleaving of APP. We confirmed that APP-CTF $\beta$ levels are absent in hippocampal brain tissues of BACE1 $1^{-/}$mice. The level of full-length APP (APP F.L.) was increased in BACE1 $1^{-/}$ mice, as previously reported (Pastorino et al., 2004). The level of APP-CTF $\alpha$ is expected to increase by compensation of $\alpha$-secretase activity in the absence of BACE1, and we observed that its level was increased in $\mathrm{BACE}^{-/-}$mice compared to BACE1 $1^{+/+}$mice (Fig. 1C).

\section{Lack of BACE1 increases NPC proliferation without affecting NPC survival}

To examine whether BACE1 affects the proliferation of NPCs, 2-month-old BACE1 $1^{+/+}, \mathrm{BACE} 1^{+/-}$, and BACE1 $1^{-/}$ mice were injected with $\mathrm{BrdU}$ and sacrificed $1 \mathrm{~d}$ after injection. The total number of $\mathrm{BrdU}^{+}$cells was subsequently determined for each animal. We observed a marked increase in the number of $\mathrm{BrdU}^{+}$cells in BACE1 $1^{-/}$ mice compared to $\mathrm{BACE} 1^{+/+}$and $\mathrm{BACE} 1^{+/-}$mice (Fig. $2 A, B)$. In addition to the BrdU analysis, we also quantified the number of cells expressing Ki67, a cellular marker for proliferation. As observed with BrdU, the number of $\mathrm{Ki} 67^{+}$ cells was significantly higher in 2-month-old BACE1 $1^{-1-}$ mice compared to age-matched $\mathrm{BACE} 1^{+/+}$and $B A C E 1^{+/-}$mice (Fig. 2C,D). The effects of the partial loss of BACE1 activity in BACE1 ${ }^{+/-}$mice did not increase NPC proliferation in both BrdU and Ki67 analyses. These results suggest that complete loss of BACE1 increased NPC proliferation in DG of adult mice.

To examine whether BACE1 activity affects survival of NPCs, parallel cohorts of mice were sacrificed 4 weeks after BrdU injection. The total number of $\mathrm{BrdU}^{+}$cells was determined for each animal. A measure of cell survival was provided by expressing the number of $\mathrm{BrdU}^{+}$cells at 4 weeks after BrdU injection as a percentage of the overall average number of $\mathrm{BrdU}^{+}$cells at $1 \mathrm{~d}$ postinjection for each respective genotype. We failed to observe any differences in cell survival across the three genotypes (Fig. $2 E)$.

\section{Lack of BACE1 impairs neuronal fate differentiation of newborn cells}

NPCs that reach maturity are fated to become either granule neurons or glial cells. To determine the effect of BACE1 activity on the differentiation of newborn NPCs, we performed triple-labeling studies using anti-BrdU antibodies combined with antibodies specific for neuronal, glial, or oligodendrocytic lineages 4 weeks post BrdU injection (Fig. $3 A-F$ ). We examined expression of the following markers: NeuN, a mature neuronal marker; glial fibrillary acidic protein (GFAP), an astrocyte marker; dou- 


\section{A}
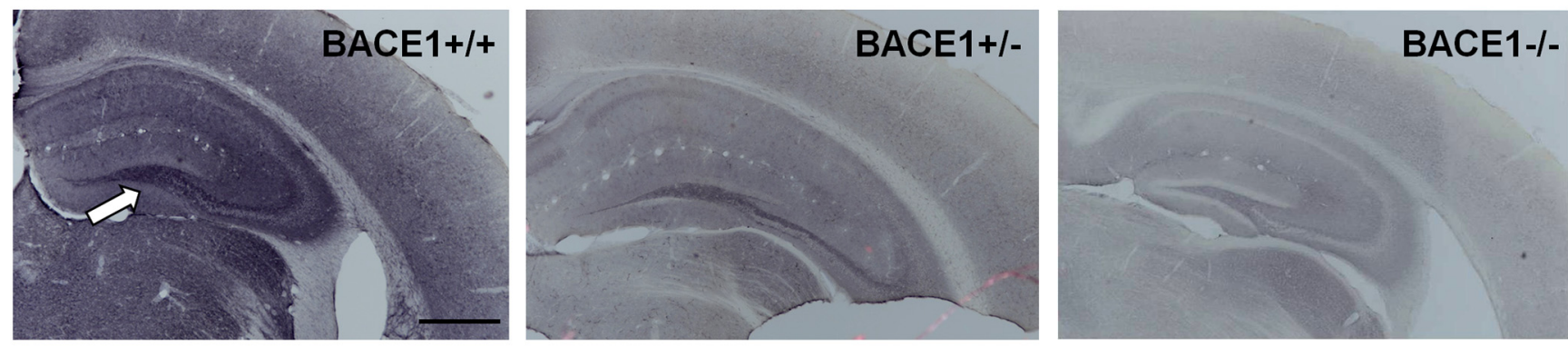

B

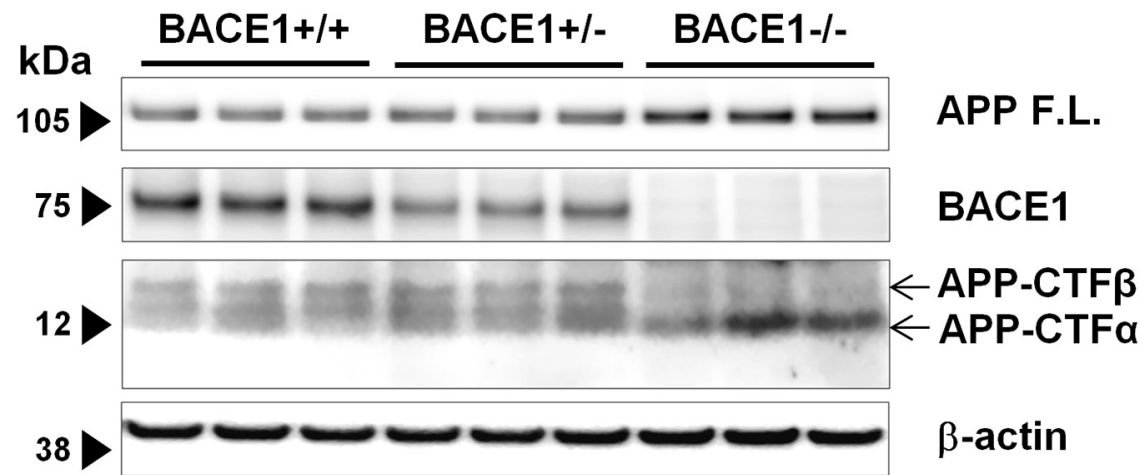

C

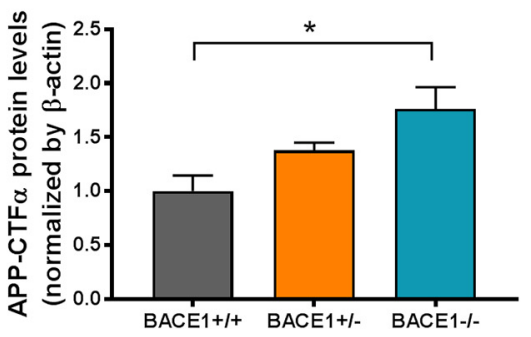

Figure 1. BACE1 is not expressed in BACE1 ${ }^{-/}$mice. $\boldsymbol{A}$, BACE1 expression was assessed in coronal sections of 2-month-old $\mathrm{BACE}^{+/+}$(left), BACE1 ${ }^{+/-}$(middle), and BACE1-/- (right) mice using immunohistochemistry with a commercial BACE1 antibody. BACE1 immunoreactivity is present throughout BACE1 $1^{+/+}$sections, with higher levels in the mossy fiber pathway of the hippocampus (white arrow). Scale bar, $500 \mu \mathrm{m}$. Conversely, there is no BACE1 immunoreactivity in BACE1 ${ }^{-1}$ brain sections. B, BACE1 expression is attenuated in BACE1 $1^{+/-}$and abrogated in BACE1 $1^{-/}$mice. The expression and activity of BACE1 was assessed in BACE1 ${ }^{+/+}$, $\mathrm{BACE}^{+/-}$, and $\mathrm{BACE} 1^{-/}$mice with Western blot. BACE1 is expressed robustly in BACE $1^{+/+}$brain tissues, is weakly expressed in BACE1 $1^{+/-}$brain tissues, and is not expressed in BACE1 $1^{-/}$brain tissues, while $\beta$-actin controls are expressed equally in all three. APP-CTF $\alpha$, a product of the enzymatic cleaving of APP by $\alpha$ secretase, is present in tissues from all three genotypes. However, APP-CTF $\beta$, a product of the enzymatic cleaving of APP by BACE1, is present in BACE $1^{+/+}$and BACE $1^{+/-}$tissues, but not in BACE1 $1^{-/-}$ tissues. $\boldsymbol{C}$, Densitometric analysis of APP-CTF $\alpha$. $F_{(2,6)}=6.557, p=0.0309 ; *, p<0.05$.

blecortin (DCX), an immature neuronal marker; and $\mathrm{O} 2$, an oligodendrocyte-specific marker.

On examination of $\mathrm{BrdU}^{+}$cells colabeled with either NeuN or GFAP, the proportion of $\mathrm{BrdU}^{+}$cells expressing NeuN was decreased in $\mathrm{BACE} 1^{-/-}$compared to BACE $1^{+/+}$mice (Fig. $3 A, B$ ). This finding demonstrates that eliminating BACE1 activity impairs neuronal differentiation of newborn cells in the adult DG. No differences were observed in the proportion of $\mathrm{BrdU}^{+}$cells colabeled with GFAP across the three genotypes, indicating that BACE1 does not affect the differentiation of NPCs into astrocytic lineages in the adult brain. Importantly, the proportion of $\mathrm{BrdU}^{+}$cells that were labeled with neither NeuN nor GFAP was higher in BACE1 ${ }^{-1-}$ mice than in either $\mathrm{BACE} 1^{+/+}$or $\mathrm{BACE} 1^{+/-}$mice, between which no differences were observed.

It is possible that this pool of seemingly undifferentiated $\mathrm{BrdU}^{+}$cells in BACE1 $1^{--}$mice is partly comprised of immature neurons, and that some consequences of the $B A C E 1^{-/}$genotype include a delay of neuronal maturation. Neurons developing in BACE1 ${ }^{-/-}$mice may be stalled at immature stages and fail to reach a fully mature phenotype; maturation may occur at different rates in the DG of $\mathrm{BACE}^{-/-}$mice. As a result, $\mathrm{BrdU}^{+}$cells were additionally assessed for colabeling with NeuN or DCX to determine if BACE1 regulates the rate of neuronal maturation (Fig. $3 C, D$ ). This experiment also aimed to better characterize the pool of $\mathrm{BrdU}^{+}$cells in $\mathrm{BACE} 1^{-/-}$mice that adopted neither a mature neuronal nor an astrocytic fate. Again, the proportion of $\mathrm{BrdU}^{+}$cells expressing NeuN was decreased in $\mathrm{BACE} 1^{-1-}$ compared to BACE1 $1^{+/+}$ mice, confirming that a lack of BACE1 activity impaired neuronal differentiation of newborn NPCs. No differences were observed in the proportion of $\mathrm{BrdU}^{+}$cells colabeled with DCX across the three genotypes, indicating that BACE1 does not affect the rate of maturation of newborn neurons. Importantly, an increased proportion of $\mathrm{BrdU}^{+}$ cells that were neither labeled with NeuN nor with DCX, and that therefore did not adopt a neural fate, was observed in $\mathrm{BACE} 1^{-/-}$compared to $\mathrm{BACE} 1^{+/+}$and $B A C E 1^{+/-}$mice.

BACE1 regulates the process of myelination and myelin sheath thickness in the central nerves. The genetic deletion of BACE1 delays the process of neuregulindependent myelination and reduces myelin thickness $(\mathrm{Hu}$ et al., 2006; Willem et al., 2006). Thus, the hypomyelina- 
A
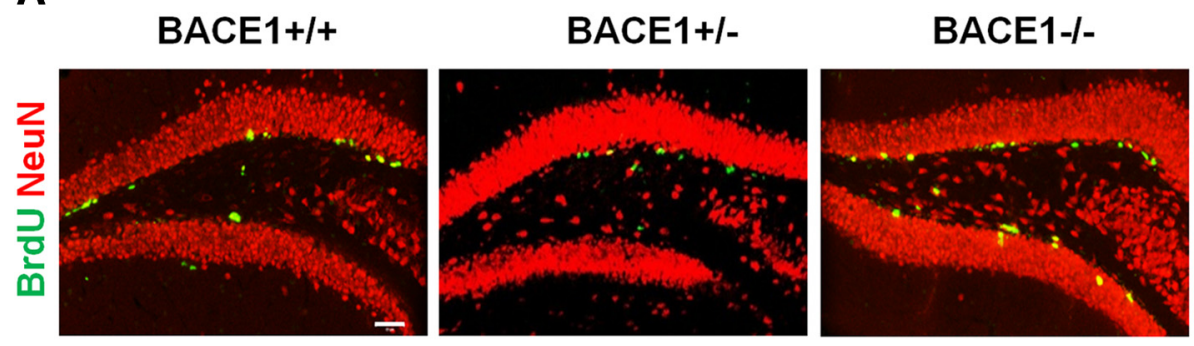

C
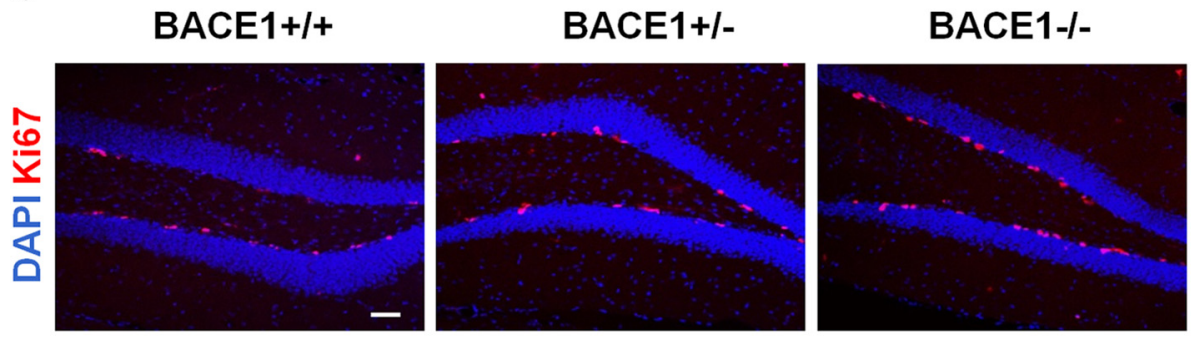

B

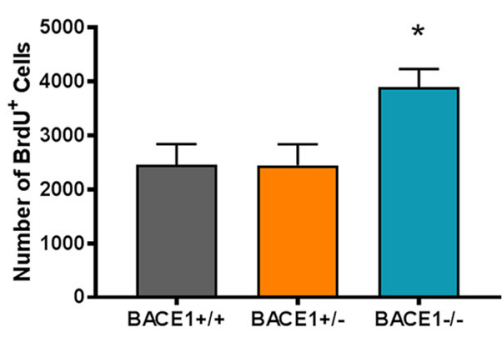

D

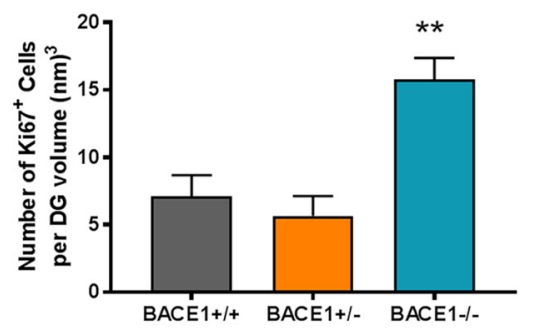

E

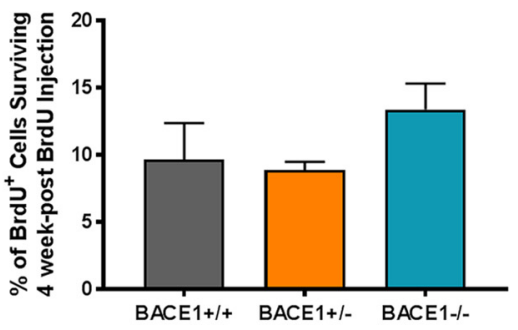

Figure 2. Loss of BACE1 increases NPC proliferation without affecting NPC survival. $\boldsymbol{A}$, Photomicrographs of BrdU ${ }^{+}$cells $1 \mathrm{~d}$ after BrdU injection in the DG of BACE1 $1^{+/+}, \mathrm{BACE}^{+/-}$, and BACE1 ${ }^{-/-}$mice. Green or yellow, BrdU ${ }^{+}$cells; red, NeuN ${ }^{+}$cells. Scale bar: 50 $\mu \mathrm{m} . \boldsymbol{B}$, Quantification of BrdU ${ }^{+}$cells 1 d post-BrdU injection (mean $\pm \mathrm{SEM} ; n=6$ in BACE1 ${ }^{+/+}, 6$ in BACE1 ${ }^{+/-}$, and 5 in BACE1 ${ }^{-/-}$ mice; $\left.F_{(2,14)}=4.629, p=0.0286\right) ; *, p<0.05$. C. Photomicrographs of Ki67 $7^{+}$cells in the DG of BACE1 ${ }^{+/+}$, BACE1 $^{+/-}$, and BACE1 ${ }^{-/-}$ mice. Red, Ki67 ${ }^{+}$cells; blue, $\mathrm{DAPI}^{+}$cells. Scale bar: $50 \mu \mathrm{m}$. $\boldsymbol{D}$, Quantification of Ki67 ${ }^{+}$cells (mean $\pm \mathrm{SEM} ; n=5$ in each group; $F_{(2,12)}$ $=15.52, p=0.0012) ; * *, p<0.01$. $\boldsymbol{E}$, To provide a measure of cell survival during the 4-week post-BrdU time period, the number of $\mathrm{BrdU}^{+}$cells at the 4-week post-BrdU time point was expressed as a percentage of the number present at the 1-d post-BrdU time point (mean $\pm \mathrm{SEM} ; n=6$ in BACE1 ${ }^{+/+}, 8$ in BACE1 ${ }^{+/-}$, and 5 in BACE1 ${ }^{-/-}$mice; $\left.F_{(2,16)}=1.654, p=0.2224\right)$.

tion in BACE1 ${ }^{-/}$mice may alter AHN processes in these mice; it is also possible that this pool of apparently undifferentiated cells in $\mathrm{BACE1^{-/ }}$ mice may be oligodendrocytes that are being overproduced as a compensatory mechanism. To determine if BACE1 regulates the production of oligodendrocytes, BrdU ${ }^{+}$cells were additionally assessed for colabeling with NeuN or O2. The proportion of $\mathrm{BrdU}^{+}$cells expressing NeuN was decreased in $\mathrm{BACE}^{-/-}$compared to BACE1 ${ }^{+/+}$mice, yet again confirming that a lack of BACE1 activity impaired neuronal differentiation of newborn NPCs (Fig. 3E,F). However, no differences were observed in the proportion of $\mathrm{BrdU}^{+}$ cells colabeled with $\mathrm{O} 2$ across the three genotypes, indicating that BACE1 does not affect the production of oligodendrocytes. Importantly, an increased proportion of $\mathrm{BrdU}^{+}$cells that were labeled with neither NeuN nor O2 was observed in $\mathrm{BACE} 1^{-/-}$compared to both BACE1 $1^{+/+}$ and $\mathrm{BACE} 1^{+/-}$mice.
The effect of decreased BACE1 activity on mature neuronal fate in $\mathrm{BACE} 1^{+/-}$mice is less clear. In the immunostaining assay with BrdU, NeuN, and GFAP, no differences were observed in the proportion of $\mathrm{BrdU}^{+}$ cells colabeled with NeuN between BACE $1^{+/-}$and either $\mathrm{BACE}^{+/+}$or BACE1 $1^{-/}$mice (Fig. $3 B$ ). However, in the separate immunostaining with $\mathrm{BrdU}, \mathrm{NeuN}$, and either DCX or O2, we did observe a difference between $B A C E 1^{+/-}$and BACE1 ${ }^{-/}$mice but not between BACE1 ${ }^{+/-}$ and BACE $1^{+/+}$mice (Fig. 3D,F).

\section{Discussion}

The present study investigated whether BACE1 regulates AHN in BACE1-null mice. We found that complete loss of BACE1 increased NPC proliferation in the DG of adult mice. Our results are in contrast with a previous report showing that inhibition of BACE1 activity decreases proliferation of cultured human embryonic stem cells (hESCs; Porayette et al., 2009). It is possible that the 
A
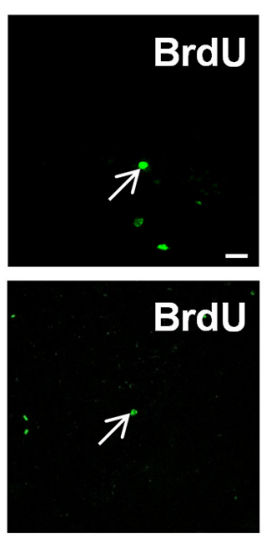

C
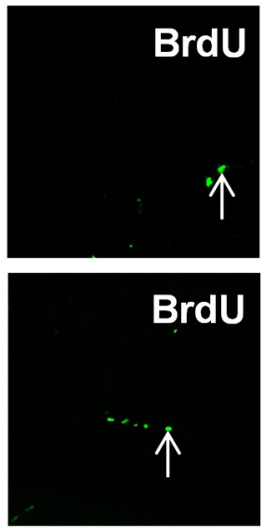

E

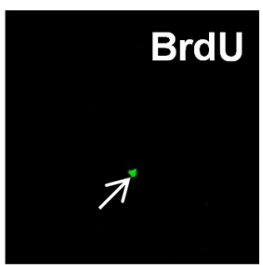

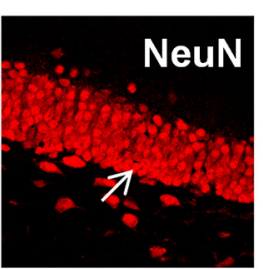
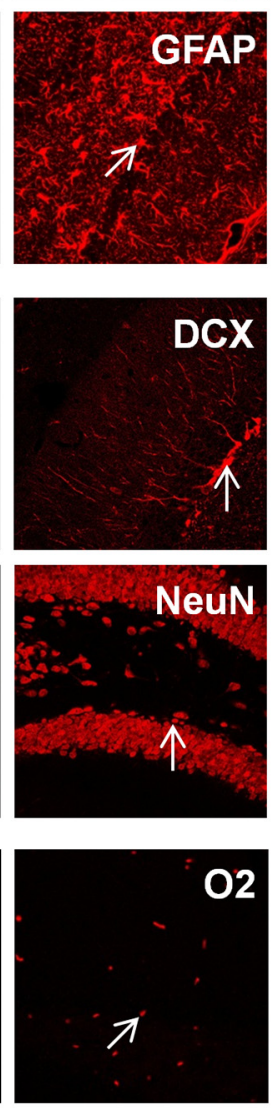
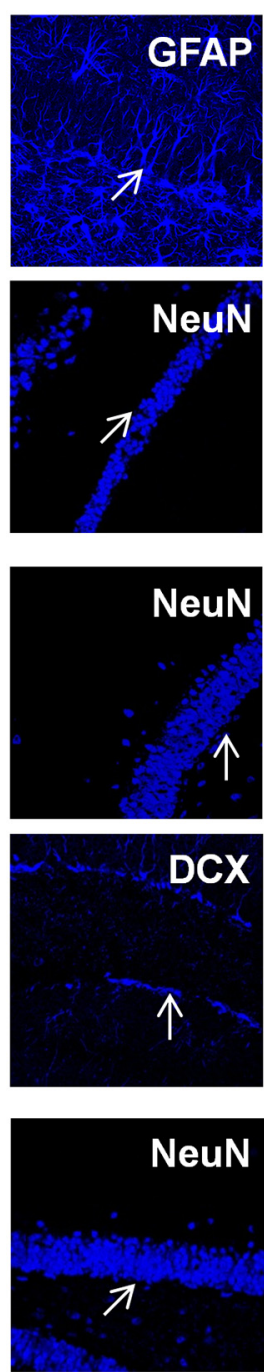
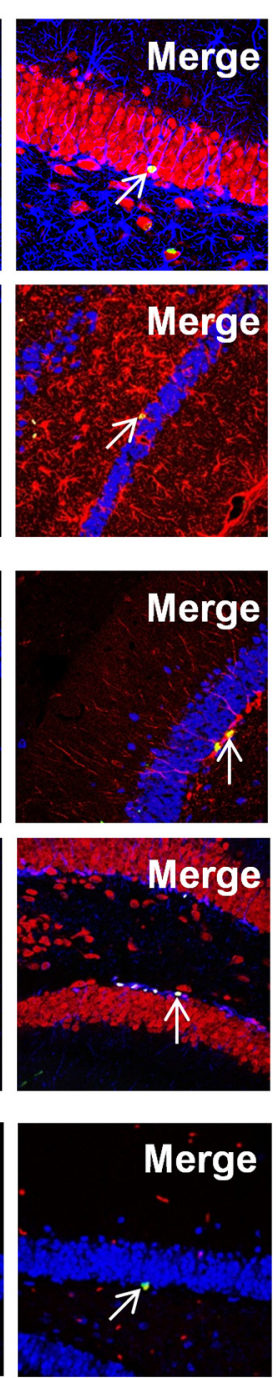

B

BACE1+/+

BACE1+/-

BACE1-/

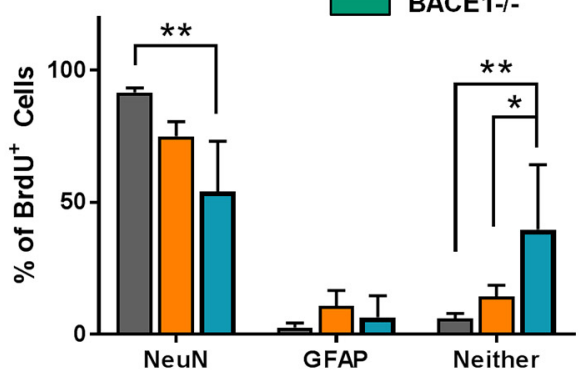

D
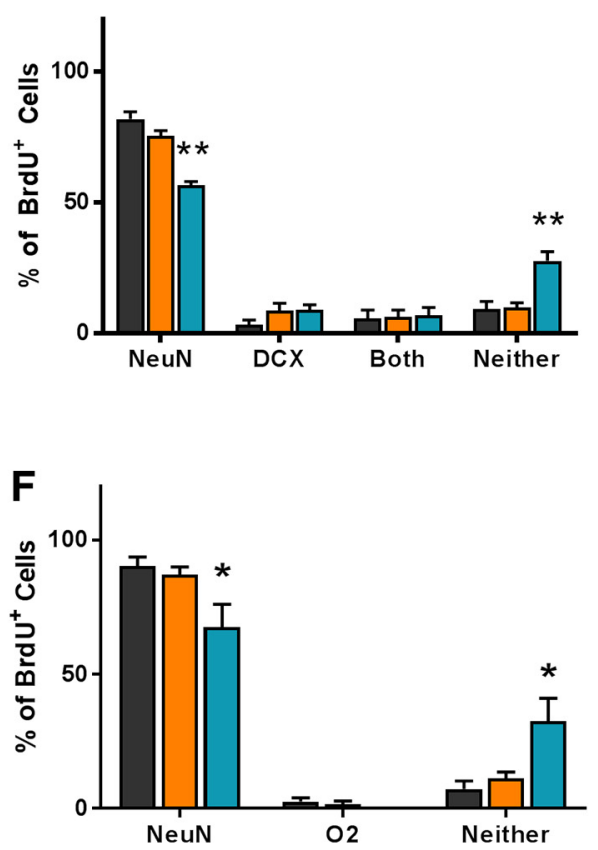

G

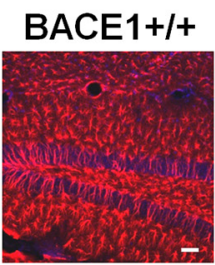

BACE1+/-

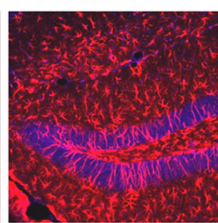

H

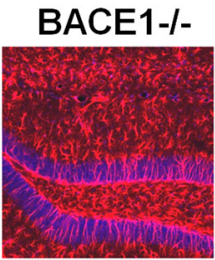

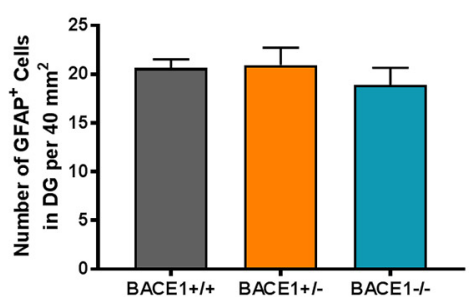

I

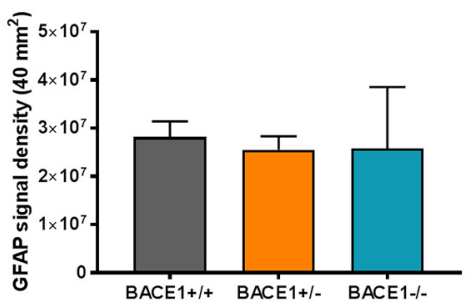

Figure 3. Loss of BACE1 alters neuronal fate differentiation of NPCs. $\boldsymbol{A}$, Representative confocal images of BrdU ${ }^{+}$cells colabeled with NeuN (upper panels) or GFAP (lower panels). Arrows indicate the position of BrdU ${ }^{+}$cells. Scale bar: $20 \mu \mathrm{m}$. $\boldsymbol{B}$, Percentage of BrdU ${ }^{+}$ cells colabeled with NeuN or GFAP, or neither of them (mean \pm SEM; $n=6$ in BACE1 ${ }^{+/+}, 8$ in BACE1 ${ }^{+/-}$, and 5 in BACE1 ${ }^{-/-}$mice). For NeuN, $F_{(2,16)}=9.501, p=0.0019$. For GFAP, $F_{(2,16)}=0.786, p=0.4725$. For neither, $F_{(2,16)}=7.551, p=0.0049 ; *, p<0.05$; $* *, p<0.01$. C, Representative confocal images of BrdU ${ }^{+}$cells colabeled with DCX but not NeuN (upper panels), or with DCX and NeuN (lower panels). $\boldsymbol{D}$, Percentage of BrdU ${ }^{+}$cells colabeled with NeuN or DCX, both, or neither of them (mean \pm SEM; $n=6$ in $\mathrm{BACE}^{+/+}, 8$ in BACE1 ${ }^{+/-}$, and 5 in BACE1 ${ }^{-/-}$mice). For NeuN, $F_{(2,16)}=28.34, p<0.0001$. For DCX, $F_{(2,16)}=1.566, p=0.2392$. For both, $F_{(2,16)}=0.03229, p=0.9863$. For neither, $F_{(2,16)}=13.63, p=0.0004 ; * *, p<0.01$. E. Representative confocal images of BrdU ${ }^{+}$ cells colabeled with O2. $\boldsymbol{F}$, Percentage of $\mathrm{BrdU}^{+}$cells colabeled with NeuN or O2, or neither of them (mean $\pm \mathrm{SEM}$; $n=4$ in $\mathrm{BACE}^{+/+}, 6$ in $\mathrm{BACE}^{+/-}$, and 4 in BACE1 ${ }^{-1-}$ mice). For NeuN, $F_{(2,11)}=5.607, p=0.0210$. For O2, $F_{(2,11)}=1.235, p=0.3283$. For neither, $F_{(2,11)}=7.3, p=0.0096 ; *, p<0.05$. G, Representative confocal images of GFAP ${ }^{+}$astrocytes in the DG of BACE1 ${ }^{+/+}$, BACE1 $^{+/-}$, and BACE $1^{-1-}$ mice. Red, GFAP ${ }^{+}$cells; blue, NeuN ${ }^{+}$cells. Scale bar: $50 \mu \mathrm{m}$. $\boldsymbol{H}$, Quantification of GFAP ${ }^{+}$cells (mean $\pm \mathrm{SEM} ; n=5$ per group; $\left.F_{(2,12)}=0.5162, p=0.6095\right)$. I, GFAP signal intensity (mean $\pm \mathrm{SEM} ; n=5$ per group; $F_{(2,12)}=0.0344, p=0.9662$ ). 
effects of BACE1 on NPC proliferation are age dependent and/or non-cell autonomous in mice, which would account for the differences between the present results and those from the previous study. It is also possible that the increased NPC proliferation in our BACE1 $1^{-1-}$ mice is a result of compensation of soluble $\operatorname{APP} \alpha(\operatorname{sAPP} \alpha)$, which has been shown to stimulate NPC proliferation (Baratchi et al., 2012), and is elevated when BACE1 is absent or inhibited (Nishitomi et al., 2006). In any event, the findings from this study suggest that BACE1 inhibition during adulthood increases NPC proliferation.

We also demonstrated that the absence of BACE1 activity produced a pool of NPCs that adopts neither a neuronal, an astrocytic, nor an oligodendrocytic fate, and thus appears to be undifferentiated. Further studies are required to elucidate mechanisms by which $A H N$ is altered in $\mathrm{BACE} 1^{-/-}$mice. BACE1-null mice in early developmental stages have been found to have decreased hippocampal neurogenesis and a corresponding increase in astrogenesis compared to wild-type counterparts, due to BACE1 cleavage of jagged-1 and consequent changes in the Notch signaling pathway in BACE1-null mice ( $\mathrm{Hu}$ et al., 2013). Studies have also shown that SAPP $\beta$ induces differentiation of human embryonic stem cells toward a neural fate (Freude et al., 2011). Thus, the absence of $\mathrm{SAPP} \beta$ in BACE $1^{-/-}$mice may alter adult neuronal differentiation. However, other studies conversely demonstrated that downregulation of BACE1 with siRNA is associated with an increase in several neurogenesis markers at the RNA and protein levels, suggesting that decreased BACE1 activity increases neurogenesis (Modarresi et al., 2011). It has also been shown that SAPP $\beta$ promotes astrogenesis in cultured hippocampal NPCs, suggesting that BACE1 enzymatic activity promotes astrogenesis over neurogenesis (Baratchi et al., 2012). The present finding that astrogenesis was unaffected by BACE1 activity reflects the possibility that the regulatory effects of BACE1 on astrogenesis are specific to the developmental stage of the animal, and that the role of the Notch signaling pathway in promoting astrogenesis is not maintained in adulthood. Astrogliosis has been shown to be affected by the loss of BACE1 in early developmental stages (Hu et al., 2013). However, no differences were observed in the number of $\mathrm{GFAP}^{+}$cells and intensity of GFAP signal in the DG across our adult BACE $1^{+/+}$, $B A C E 1^{+/-}$, and $B A C E 1^{-/}$mice at 2 months of age (Fig. $3 G-I)$.

Our studies thus raise the concerning possibility of creating a population of undifferentiated cells, in a stem cell-like state, for an extended period time in the brains of AD patients being treated with BACE inhibitors. The resulting delay in neuronal differentiation might then lead to decreased myelination as has been observed in BACE1 $1^{-/}$ mice (Hu et al., 2006). These undifferentiated cells may be also impaired in their ability to integrate into functional circuitry, leading to the formation of aberrant patterns of connectivity that might be associated with the memory deficits and seizures observed in BACE1 ${ }^{-/}$mice (Kandalepas and Vassar, 2014). Future studies will be neces- sary to identify these undifferentiated cells and to investigate the roles of BACE1 on AHN in conditional BACE1 KO mice. Studies may also be performed using BACE1 inhibitors in aged mice to produce insights that are more applicable to $A D$ research.

Notably, the Merck phase 3 clinical trial of the BACE1 inhibitor, verubecestat, was terminated based on the observation of numerous adverse events including falls, weight loss, sleep disturbance, change in hair color, and suicidal ideation. These findings argue against robust inhibition of BACE1. Our findings showing that completely blocking BACE1 activity impaired AHN strongly argue against a therapeutic strategy for $A D$ that involves robustly inhibiting BACE1. However, since AHN processes were not altered in $\mathrm{BACE} 1^{+/}$mice versus $\mathrm{BACE} 1^{+/+}$ mice, a therapeutic strategy of partial inhibition of BACE1 may still warrant further study.

\section{References}

Aimone JB, Li Y, Lee SW, Clemenson GD, Deng W, Gage FH (2014) Regulation and function of adult neurogenesis: from genes to cognition. Physiol Rev 94:991-1026. CrossRef Medline

Baratchi S, Evans J, Tate WP, Abraham WC, Connor B (2012) Secreted amyloid precursor proteins promote proliferation and glial differentiation of adult hippocampal neural progenitor cells. Hippocampus 22:1517-1527. CrossRef Medline

Eriksson PS, Perfilieva E, Björk-Eriksson T, Alborn AM, Nordborg C, Peterson DA, Gage FH (1998) Neurogenesis in the adult human hippocampus. Nat Med 4:1313-1317. CrossRef Medline

Freude KK, Penjwini M, Davis JL, LaFerla FM, Blurton-Jones M (2011) Soluble amyloid precursor protein induces rapid neural differentiation of human embryonic stem cells. J Biol Chem 286: 24264-24274. CrossRef Medline

Hu X, He W, Luo X, Tsubota KE, Yan R (2013) BACE1 regulates hippocampal astrogenesis via the Jagged1-Notch pathway. Cell Rep 4:40-49. CrossRef Medline

Hu X, Hicks CW, He W, Wong P, Macklin WB, Trapp BD, Yan R (2006) Bace1 modulates myelination in the central and peripheral nervous system. Nat Neurosci 9:1520-1525. CrossRef Medline

Kandalepas PC, Vassar R (2014) The normal and pathologic roles of the Alzheimer's beta-secretase, BACE1. Curr Alzheimer Res 11: 441-449. Medline

Mahar I, Maclsaac A, Kim JJ, Qiang C, Davoli MA, Turecki G, Mechawar N (2016) Effects of neuregulin-1 administration on neurogenesis in the adult mouse hippocampus, and characterization of immature neurons along the septotemporal axis. Sci Rep 6:30467. CrossRef Medline

Ming GL, Song H (2011) Adult neurogenesis in the mammalian brain: significant answers and significant questions. Neuron 70:687-702. CrossRef Medline

Modarresi F, Faghihi MA, Patel NS, Sahagan BG, Wahlestedt C, Lopez-Toledano MA (2011) Knockdown of BACE1-AS nonproteincoding transcript modulates beta-amyloid-related hippocampal neurogenesis. Int J Alzheimers Dis 2011:929042. CrossRef Medline

Mu Y, Gage FH (2011) Adult hippocampal neurogenesis and its role in Alzheimer's disease. Mol Neurodegener 6:85. CrossRef Medline

Nishitomi K, Sakaguchi G, Horikoshi Y, Gray AJ, Maeda M, HirataFukae C, Becker AG, Hosono M, Sakaguchi I, Minami SS, Nakajima Y, Li HF, Takeyama C, Kihara T, Ota A, Wong PC, Aisen PS, Kato A, Kinoshita N, Matsuoka Y (2006) BACE1 inhibition reduces endogenous Abeta and alters APP processing in wild-type mice. J Neurochem 99:1555-1563. CrossRef Medline

Pastorino L, Ikin AF, Lamprianou S, Vacaresse N, Revelli JP, Platt K, Paganetti P, Mathews PM, Harroch S, Buxbaum JD (2004) BACE 
(beta-secretase) modulates the processing of APLP2 in vivo. Mol Cell Neurosci 25:642-649. CrossRef Medline

Porayette P, Gallego MJ, Kaltcheva MM, Bowen RL, Vadakkadath Meethal S, Atwood CS (2009) Differential processing of amyloidbeta precursor protein directs human embryonic stem cell proliferation and differentiation into neuronal precursor cells. J Biol Chem 284:23806-23817. CrossRef

Spalding KL, Bergmann O, Alkass K, Bernard S, Salehpour M, Huttner HB, Boström E, Westerlund I, Vial C, Buchholz BA, Possnert G, Mash DC, Druid H, Frisén J (2013) Dynamics of hippocampal neurogenesis in adult humans. Cell 153:1219-1227. CrossRef Medline

Tanzi RE, Bertram L (2005) Twenty years of the Alzheimer's disease amyloid hypothesis: a genetic perspective. Cell 120:545-555. CrossRef Medline
Vassar R (2014) BACE1 inhibitor drugs in clinical trials for Alzheimer's disease. Alzheimers Res Ther 6:89. CrossRef Medline

Willem M, Garratt AN, Novak B, Citron M, Kaufmann S, Rittger A, DeStrooper B, Saftig P, Birchmeier C, Haass C (2006) Control of peripheral nerve myelination by the beta-secretase BACE1. Science 314:664-666. CrossRef Medline

Zhao C, Deng W, Gage FH (2008) Mechanisms and functional implications of adult neurogenesis. Cell 132:645-660. CrossRef Medline

Zhao J, Fu Y, Yasvoina M, Shao P, Hitt B, O'Connor T, Logan S, Maus E, Citron M, Berry R, Binder L, Vassar R (2007) Beta-site amyloid precursor protein cleaving enzyme 1 levels become elevated in neurons around amyloid plaques: implications for Alzheimer's disease pathogenesis. J Neurosci 27:3639-3649. CrossRef 